\title{
Interconnection between flowering time control and activation of systemic acquired resistance
}

\author{
Zeeshan Z. Banday and Ashis K. Nandi * \\ School of Life Sciences, Jawaharlal Nehru University, New Delhi, India
}

The ability to avoid or neutralize pathogens is inherent to all higher organisms including plants. Plants recognize pathogens through receptors, and mount resistance against the intruders, with the help of well-elaborated defense arsenal. In response to some local infections, plants develop systemic acquired resistance (SAR), which provides heightened resistance during subsequent infections. Infected tissues generate mobile signaling molecules that travel to the systemic tissues, where they epigenetically modify expression of a set of genes to initiate the manifestation of SAR in distant tissues. Immune responses are largely regulated at transcriptional level. Flowering is a developmental transition that occurs as a result of the coordinated action

OPEN ACCESS

Edited by:

Jean Toby Greenberg,

The University of Chicago, USA

Reviewed by:

Robin Katrina Cameron,

McMaster University, Canada

Yusuke Saijo,

Max Planck Institute for Plant

Breeding Research, Germany

*Correspondence:

Ashis K. Nandi,

School of Life Sciences, Jawaharlal

Nehru University, Room 415,

New Delhi-110067, Delhi, India

ashis_nandi@yahoo.com

Specialty section:

This article was submitted to

Plant-Microbe Interaction, a section of the journal Frontiers in Plant Science

Received: 11 November 2014 Accepted: 04 March 2015 Published: 19 March 2015

Citation:

Banday ZZ and Nandi AK (2015) Interconnection between flowering time control and activation of systemic acquired resistance.

Front. Plant Sci. 6:174. doi: 10.3389/fpls.2015.00174 of large numbers of transcription factors that respond to intrinsic signals and environmental conditions. The plant hormone salicylic acid (SA) which is required for SAR activation positively regulates flowering. Certain components of chromatin remodeling complexes that are recruited for suppression of precocious flowering are also involved in suppression of SAR in healthy plants. FLOWERING LOCUS D, a putative histone demethylase positively regulates SAR manifestation and flowering transition in Arabidopsis. Similarly, incorporation of histone variant H2A.Z in nucleosomes mediated by PHOTOPERIOD-INDEPENDENT EARLY FLOWERING 1, an ortholog of yeast chromatin remodeling complex SWR1, concomitantly influences SAR and flowering time. SUMO conjugation and deconjugation mechanisms also similarly affect SAR and flowering in an SA-dependent manner. The evidences suggest a common underlying regulatory mechanism for activation of SAR and flowering in plants.

Keywords: SAR, flowering, SA, FLD, chromatin remodeling, epigenetic

\section{Introduction}

Immobility precludes plants from evading pathogens. However, the presence of strong immune system most often keeps them healthy. Higher animals like vertebrates, are capable of retaining an infection memory with the help of dedicated immune system and circulatory cells. The generated infection memory facilitates stronger immune response during subsequent interactions with the same pathogen (adaptive immunity). Despite not having dedicated immune cells, plants are equally capable of using infection-induced molecular memories to resist subsequent infections. This heightened resistance based on past experience is called systemic acquired resistance (SAR; Ross, 1961). Unlike adaptive immunity-based learning in animals, SAR-mediated protection in 
plants is not limited to the same pathogen, but is effective against a wide range of microbial pathogens (Sticher et al., 1997; Durrant and Dong, 2004).

While pre-existing cell wall and structural components such as cuticular wax provide resistance against pathogens, most defense responses are induced upon pathogen infection. Resistance against pathogens in plants relies both on fortification of structural barriers and production of antimicrobial chemicals and proteins. Microbe/pathogen associated molecular patterns (MAMPs/PAMPs) are recognized by the plasma membrane (PM) resident pattern recognition receptors (PRRs; Nimchuk et al., 2003). Recognition of MAMP/PAMP by PRRs activates signaling cascades involving kinases, proteases, protein modifiers and transcription regulators, which eventually results in cell wall strengthening, production of antimicrobial proteins and phytoalexins (Schwessinger and Ronald, 2012). The defense hormones such as salicylic acid (SA), ethylene (ET), and jasmonic acid (JA) function as second messengers of the signaling events (Verhage et al., 2010). PRR activation induces biosynthesis of these hormones, which in turn leads to transcriptional reprogramming in favor of defense. Pathogen infection induces transcription of large number of genes, a subset of these are pathogenesis related $(P R)$ genes (van Loon et al., 2006). Several PR proteins are secreted out of the host cell and negatively affect the growth of pathogens due to their antimicrobial properties (van Loon et al., 2006). Immune responses as described above, triggered by activation of PRRs is known as pattern triggered immunity (PTI). Some pathogens, however, release effector molecules to suppress the plant PTI response (Jones and Dangl, 2006). Plants can overcome the effects of pathogen effectors using $\mathrm{R}$ gene-mediated resistance, in which $\mathrm{R}$ receptors interact directly or indirectly with pathogen effectors to initiate effector-triggered immunity (ETI). ETI is an exaggerated form of PTI (Jones and Dangl, 2006).

When a plant succeeds in restricting the growth of a pathogen, it develops SAR; a state of preparedness that provides elevated resistance during subsequent infections (Durrant and Dong, 2004; Iriti and Faoro, 2007; Vlot et al., 2008). Besides pathogens, certain chemicals such as SA and its chemical analogs are capable of inducing SAR in plants (Lawton et al., 1996). During the SAR inducing infection, mobile signals are synthesized in the infected tissue and get distributed throughout the plant, via phloem (Figure 1; Guedes et al., 1980; Tuzun and Kuc, 1985). It has been demonstrated that upon localized pathogen inoculation, the pathogen free distal tissues show immune responses like the infected tissues, but to a moderate level. For example, distal tissues show fortification of cell wall, accumulation defense hormones and expression of PR-proteins (Ward et al., 1991; Ryals et al., 1996; Fu and Dong, 2013). But more importantly, an experienced plant activates priming, a SAR induced mechanism that results in robust induction of defense responses compared to a naive plant, during subsequent pathogen infections (Jung et al., 2009; Slaughter et al., 2012; Singh et al., 2013). Genetic and biochemical experiments, mostly on model plants, identified several compounds such as SA, methyl salicylate, JA, dihydroabetinal, azelaic acid, glycerol3-phosphate, pipecolic acid, and lipid transfer protein DIR1 as

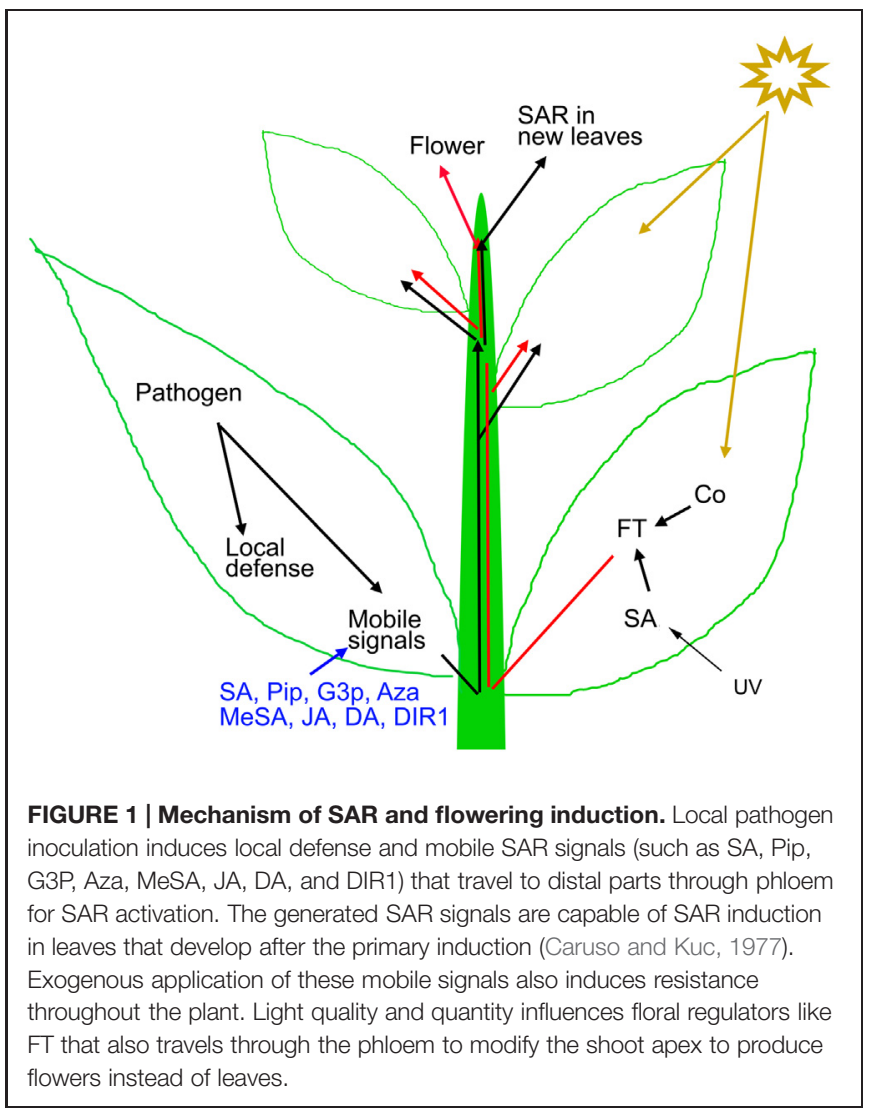

potential mobile signals of SAR (Dempsey and Klessig, 2012; Navarova et al., 2012; Champigny et al., 2013). Petiole exudates enriched for phloem sap collected from pathogen-inoculated leaves, carrying these mobile signals are capable of inducing SAR in naive plants (Chaturvedi et al., 2008; Chanda et al., 2011).

Mechanism of the development of infection memory, subsequent to receiving the mobile signal in distal tissues, is not elucidated well. The mobile signals by themselves are not antimicrobial (Jung et al., 2009; Chanda et al., 2011; Chaturvedi et al., 2012; Navarova et al., 2012). The metabolic signals do not directly provide SAR, as they are elevated only transiently, while SAR lasts for weeks to months as observed in cucumber, watermelon, muskmelon, and other plants (Caruso and Kuc, 1977; Kuc and Richmond, 1977). Thus, for the induction of SAR, the systemic tissues must perceive and decode the SAR signals. Recent studies, mostly with the model plant Arabidopsis provide evidence that upon infection, epigenetic modifications takes place in systemic tissues, which contribute to infection memory formation. Promoters of the plant specific WRKY transcription factors have been reported to accumulate elevated levels of modified histones that are normally associated with epigenetic control of gene expression (Jaskiewicz et al., 2011; Luna et al., 2012; Singh et al., 2014b). Modified histones on WRKY genes involved in SAR could be part of infection memory. It's not clear how this epigenetic mechanism relates to SAR memory. 
Recent studies indicate a close interconnection between flowering time control and SAR activation mechanisms. The transition to flowering is an irreversible process for annual plants, when the shoot apical meristem becomes an inflorescence meristem that produces flowers instead of leaves. The timing of this transition is a major factor for the reproductive success of plants. Regulation of flowering time involves complex regulatory network consisting of multiple set of genes (Simpson and Dean, 2002). The flowering molecular switch ensures that plants flower at a time when internal resources are adequate and the ambient environmental conditions are optimum for pollination and seed development (Simpson et al., 1999). A large number of gene products affect both flowering and SAR (Figure 2). This review article discusses the possible mechanistic overlap in regulation of flowering time and SAR.

\section{Flowering Control by Salicylic Acid and other SAR Inducers}

Functions of SA and its derivatives are intricately associated with SAR. SA and its chemical analogs are potential SAR inducers when exogenously applied to plants (Yalpani et al., 1991; Gaffney et al., 1993). When a plant is infected by a pathogen, high level of SA accumulates in the pathogen-infected tissue and to a lesser extent in pathogen free systemic tissues (Metraux et al., 1990; Nandi et al., 2004). SA promotes nuclear localization and activation of NON-EXPRESSOR OF PR-1 (NPR1), a trans-activator protein, which is required for SAR (Kinkema et al., 2000; Wu et al., 2012). NPR1 interacts with TGA transcription factors, and together induce expression of $P R$ genes (Dong, 2004). Expression of PR-1 gene is typically associated with the activation of SA signaling and thus serves as its marker. The mutants such as suppressor of fatty acid desaturase 1 (sfd1), reduced systemic immunity 1 (rsi1), azelaic acid induced 1 (azi1) of Arabidopsis that are impaired in SAR induction are defective

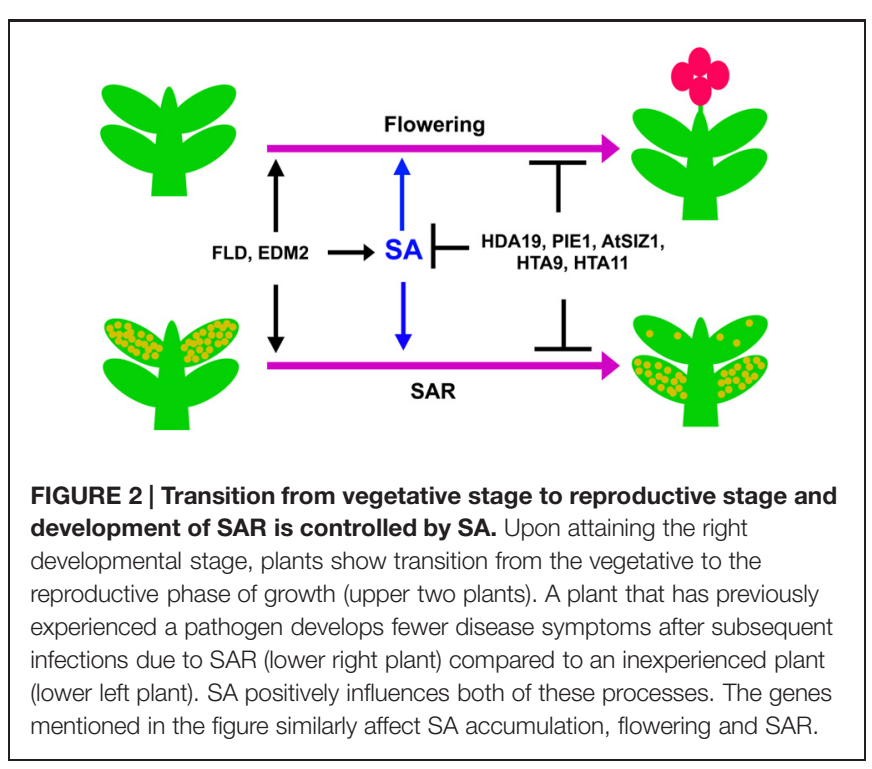

in systemic SA accumulation, and priming induced expression of PR-1 (Chaturvedi et al., 2008; Jung et al., 2009; Singh et al., 2013). SA has been implicated as an integral component of SAR signaling (Ryals et al., 1996; Sticher et al., 1997; Conrath, 2011; Fu and Dong, 2013).

Interestingly, SA also influences flowering time to a great extent. Involvement of $\mathrm{SA}$ in common regulation of SAR/pathogen response and flowering is reflected in many reports (discussed in the following sections; Figure 2). ENHANCED DOWNY MILDEW 2 (EDM2) gene of Arabidopsis is required for $R P P 7$-mediated resistance against downy mildew pathogen Hyaloperonospora parasitica (Eulgem et al., 2007). The mutants of EDM2 fail to accumulate pathogen induced SA, and also cause flowering time delay (Tsuchiya and Eulgem, 2010).

\section{Effect of Light on SA, SAR, and Flowering}

Light plays very important role in biosynthesis of SA and immune responses (Zeier et al., 2004; Kangasjarvi et al., 2012). Pathogen induced SA biosynthesis takes place in chloroplast, in light (UVC) dependent manner (Fragniere et al., 2011). A large number of genes that are induced upon flg22 (bacterial flagellin derived PAMP peptide) treatment require light (Sano et al., 2014). Light composition, intensity, and duration affect defense responses (Chandra-Shekara et al., 2006; Griebel and Zeier, 2008; Ballare et al., 2012; de Wit et al., 2013). Red light stimulates disease resistance against many pathogens (Islam et al., 2008; Wang et al., 2010). In contrast, addition of far-red light (leading to reduced red:far-red ratio) negatively influences defense responses (de Wit et al., 2013). Plants perceive red and far-red lights by two interconvertible forms of phytochrome photo-receptors, $\mathrm{Pr}$ and $\mathrm{Pfr}$, which absorb red and far-red light, respectively. The $\operatorname{Pr}$ is the inactive form, which converts into the active form Pfr, upon absorbing red light, whereas, the Pfr form converts back into the Pr form by absorbing far-red light (Smith, 2000). The phyAphyB double mutant plants are susceptible against virulent pathogen Pseudomonas syringae pv. maculicola ES4326 (Psm; Griebel and Zeier, 2008). The results suggest that phytochrome signaling plays a very significant role in disease defense. Does phytochrome signaling have any specific role in SAR? The experimental evidence is insufficient at the present time to draw this conclusion. Griebel and Zeier, 2008, reported that the phytochrome signaling is more pertinent for SAR than local defense. However, this conclusion may be accepted with certain reservations. The phyAphyB mutant plants are highly susceptible to Psm, and support modestly higher growth of Psm carrying the avirulence gene avrRpm1 (Psm-AvrRpm1) compared to wild-type plants. The phyAphyB plants, but not the mutants of other photoreceptors such as cryptochromes $(\operatorname{cry} A \mathrm{cry} B)$ and phototropins (phot1 phot2) are defective activation of SAR. Surprisingly, authors used Psm as primary pathogen for SAR induction, against which phyAphyB plants were compromised for local defense, instead of PsmAvRpm1 (Griebel and Zeier, 2008). Moreover, other studies, such as the effect of red light in promoting disease defense, and low red-far red ratio affecting general defense responses, also counter argues for phytochromes having specific roles in SAR.

The role of light in flowering is much well-established. Amongst the environmental factors that affect flowering, light 
plays the most important role. According to the photoperiod dependence for flowering, angiosperms are grouped into longday (LD), short-day (SD), and day-neutral plants. Arabidopsis is a facultative LD plant that flowers early in LD, and show delayed flowering under SD condition. The striking similarity between SAR and photo-period induced flowering is the requirement of long distance signal movement through phloem (Figure 1; Zeevaart, 2006). Grafting and girdling experiments suggested that the flowering inducers are phloem transmissible (Knott, 1934; Chailakhyan, 1936). By the perception of the day-length effect, leaves generate a mobile signal for flowering. The signal moves to the growing apex via phloem; the apex modifies to produce flower instead of leaves (Knott, 1934; Chailakhyan, 1936). In recent years, it has been shown that the phloem mobile flowering promoting factor is a protein; flowering locus T (FT) in Arabidopsis (Corbesier et al., 2007). FT orthologs have been identified in many plants suggesting that the vascular conductance is a universal feature for flowering in plants (Tamaki et al., 2007; Varkonyi-Gasic et al., 2013; Li et al., 2014).

Interestingly, SA is also reported as an inducer of photoperiodmediated flowering. Abiotic stress such as UV-C induces expression of FT as well as flowering in SA dependent manner in Arabidopsis (Martinez et al., 2004). The transgenic plants expressing NahG fail to induce FT expression and early flowering by UV-C treatment (Martinez et al., 2004). The phloem sap, or the honeydew produced by aphid infestation, on Xanthium strumarium is capable of inducing flowering in the long-day plant Lemna gibba (Cleland and Ajami, 1974). Purification of flowering inducing component from aphid-honeydew by TLC, followed by GLC and mass-spectrometric analysis identified SA as the active ingredient of flowering inducer in phloem sap (Cleland and Ajami, 1974). Exogenous application of SA in the growing medium or in leaves, in several plants promote flowering (Cleland and Ajami, 1974; Khurana and Cleland, 1992; Wada et al., 2014). Thus, SA may be considered as a common inducer for both flowering and SAR (Figure 1). A similar dual role is also reported for pipecolic acid (Pip), another mobile signal for SAR induction (Navarova et al., 2012). Flowering inducing activity guided fractionation identified Pip and nicotinamide as flowering inducing substances in L. gibba leaf extracts (Fujioka et al., 1987).

\section{FLD Regulates the Transition to Flowering and SAR}

At a defined time in their life-cycle, annual plants undergo a developmental transition from the vegetative to the reproductive stage. This transition is controlled by environmental as well as endogenous developmental cues. The environmental factors include day length (photoperiod), quality and quantity of light (composition and photon density), prolonged cold exposure (vernalization), and nutrient and water availability, whereas, plant age and vegetative growth provide developmental cues for transition (see Amasino, 1996; Aukerman and Amasino, 1996). In Arabidopsis, mutational analysis has identified numerous genes that affect flowering time. The CONSTANS protein accumulates in long-days and positively regulates expression of FT, and SUPPRESOR OF CO 1 (SOC1), and thereby promotes flowering (Suarez-Lopez et al., 2001). In contrast, FLOWERING LOCUS $C$ (FLC) negatively regulates $F T$ and SOC1, and helps plants to avoid premature flowering (Michaels and Amasino, 1999; Helliwell et al., 2006). FLC codes for a MADS box protein that binds to promoters of FT and SOC1 repressing transcription of these genes (Helliwell et al., 2006). A large number of genes, whose expression is modulated by developmental cues and environmental factors, affect expression of FLC and control flowering time (Henderson and Dean, 2004). The FLC locus is epigenetically regulated through histone modifications. FLOWERING LOCUS D (FLD) negatively regulates expression of FLC and thereby promotes flowering (He et al., 2003; He and Amasino, 2005; Liu et al., 2007). Thus, flowering is delayed in fld loss-offunction mutants (He et al., 2003; Singh et al., 2013).

A genetic screen selecting for SAR-impaired mutants from EMS treated Arabidopsis plants, identified reduced in systemic immunity 1 (rsi1), which is a loss-of-function allele of FLD (Singh et al., 2013). The rsil mutant is defective in systemic accumulation of SA and priming of PR-1,WRKY6, and WRKY29 genes (Singh et al., 2013, 2014b). Petiole exudates from inoculated rsi1 leaves activate SAR on WT plants, whereas, SAR inducible petiole exudates from WT plants fail to induce SAR in rsi1. Moreover, SAR is not induced in rsil plants by exogenous application of SAR inducers such as dihydroabetinal and azelaic acid. Thus, the rsil and the allelic fld mutants are capable of generating SAR mobile signals after primary infection, but fail to decode the signal in the distal tissues. These data suggest that FLOWERING LOCUS $\mathrm{D}$ function is required for generating infection memory, subsequent to receiving the SAR signal. FLD expression is induced both in the primary SAR-induced and systemic tissues (Singh et al., 2013). As a consequence, FLC expression maybe suppressed in by SAR induction. Indeed, transcript analysis following SA treatment showed suppression of FLC expression (Martinez et al., 2004). Although, FLC expression is suppressed by SA, its function is probably not associated with SAR (Singh et al., 2013). The $f l c$ mutant has no defect in SAR activation, and the $f l c$ mutation does not rescue the SAR defect in the rsil/fld mutant. Thus FLD may function as branch point between flowering time control and SAR activation in Arabidopsis (Figure 3).

The mechanism of FLD expression in response to SAR induction is not known. Brassinosteroid (BR) signaling has recently been associated with FLD expression (Zhang et al., 2013b). BR is perceived by the receptor kinase, BR INSENSITIVE1 (BRI1) along with BRI1 ASSOCIATED KINASE1 (BAK1; Yang et al., 2011). Binding of BR activates both BAK1 and BRI1 through auto- and trans-phosphorylation, which in turn release the receptor-like cytoplasmic kinases BRASSINOSTEROID SIGNALING KINASES (BSKs) and CONSTITUTIVE DIFFERENTIAL GROWTH1 (CDG1; Tang et al., 2008; Kim et al., 2011). BSKs and CDG1 phosphorylate and activate BRI1 SUPPRESSOR1 (BSU1), a phosphatase that dephosphorylates BIN2 (Clouse, 2011; Kim et al., 2011). BIN2 negatively regulates BR signaling by phosphorylating and thereby promoting cytoplasmic retention of transcription 


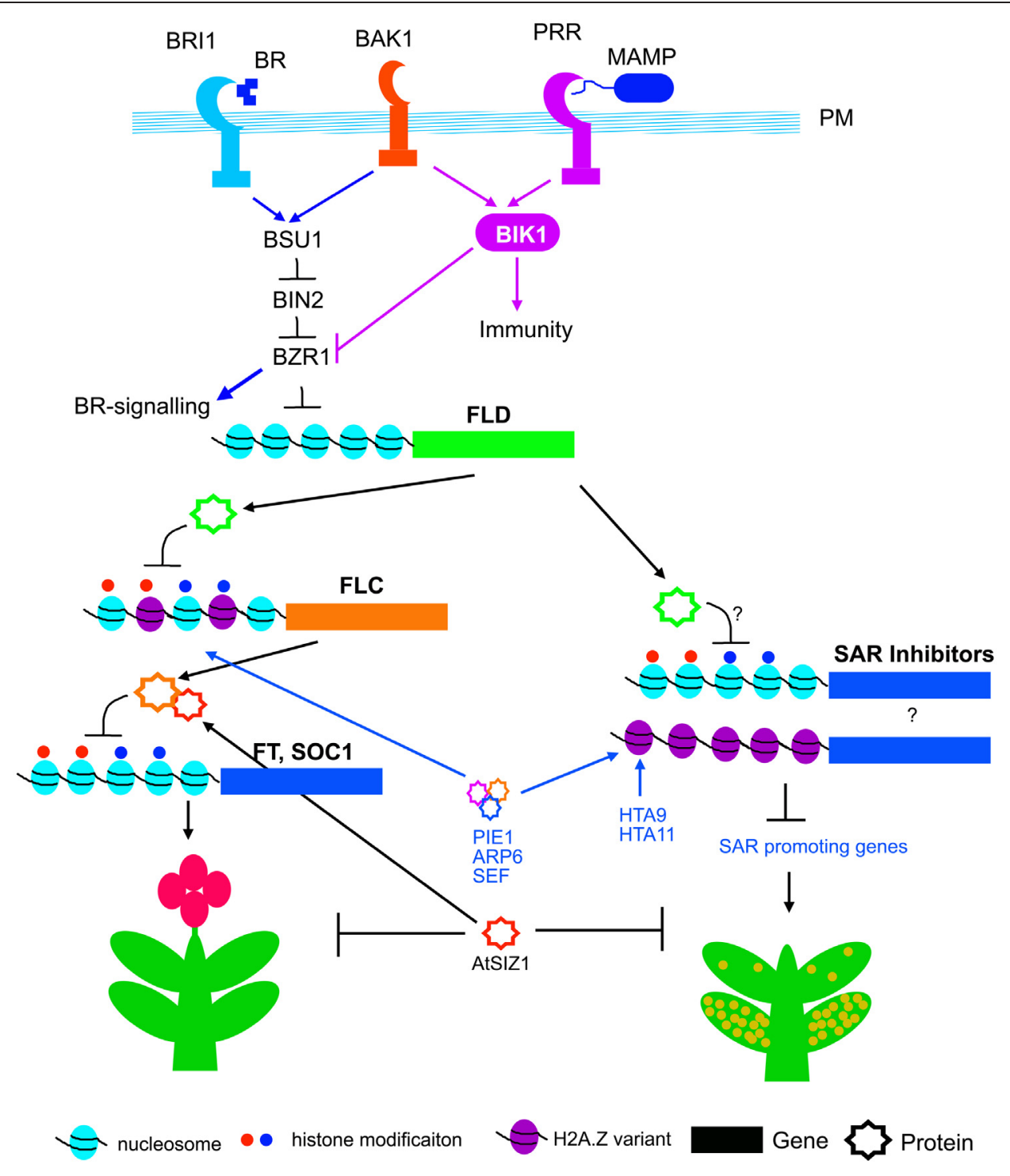

FIGURE 3 | Genetic and epigenetic control of flowering and SAR. Plasma membrane (PM) resident BAK1 associates with both BRI1 and PRRs (pattern recognition receptors) which are required for $\mathrm{BR}$ and $\mathrm{PTI}$ signaling respectively. BSU1 phosphatase is activated by BRI1 and BAK1. BSU1 dephosphorylates and inactivates BIN2, and thereby activates BZR1 and BR signaling. BZR1 negatively regulates FLD expression. Activation of PTI activates BIK1, which suppress BZR1 and thereby may promote expression of FLD. FLD transcriptionally suppress FLC, the floral repressor. FLC protein is stabilized through interaction with AtSIZ1. AtSIZ1 functions as negative regulator for both flowering and SAR. The PIE1, ARP6 and SEF complex, and HTA9, HTA11 promote histone variant incorporation and biosynthesis, and thus promote transcription of FLC and unknown SAR suppressors. factors, such as BRASSINAZOLE RESISTANT 1 (BZR1) and BRI1 EMS SUPPRESSOR1 (BES1), through interaction with 14-3-3 protein (Yang et al., 2011). Dephosphorylation of BZR1 and BES1 by protein phosphatase $2 \mathrm{~A}$, relieve cytoplasmic retention, allowing their nuclear translocation and binding to target promoters (Tang et al., 2011). Interestingly, the promoter of FLD contains one BR-responsive element (BRRE; Zhang et al., 2013b). Electrophoretic mobility shift assay (EMSA) shows that BRRE of FLOWERING LOCUS D promoter binds with the recombinant MBP-BZR1 protein but not the maltose binding protein (MBP; Zhang et al., 2013b). In addition, chromatin immuno-precipitation with GFP antibody shows enrichment of CFP-BZR1 in FLD promoter. The physical association and transcriptional analyses suggest that BZR1 binds to promoter of FLD and negatively regulates its expression (Zhang et al., 2013b). In immune signaling, FLAGELIN SENSING2 (FLS2) and ELONGATION FACTOR TU RECEPTOR (EFR), the pattern receptors for bacterial flagellin and elongation factor $\mathrm{Tu}$ respectively, heteromerize with BAK1 (Chinchilla et al., 2009; Roux et al., 2011; Sun et al., 2013). BAK1 phosphorylate BOTRYTISINDUCED KINASE1 (BIK1), a receptor-like cytoplasmic kinase that positively regulates plant immunity (Lu et al., 2010; Zhang et al., 2010). However, the BIK1 acts as a negative regulator of $\mathrm{BR}$ signaling. The bik1 mutant plants show enhancement in 
dephosphorylation of BZR1 and BES1 (Lin et al., 2013), Thus activation of BIK1 by pathogens may inactivate BZR1 (through cytoplasmic retention) and thereby induce expression of FLD (Figure 3).

\section{Chromatin Remodeling}

Eukaryotic DNA is packed into nucleosomes, which must transiently unpack during transcription. Alteration of nucleosome density, also known as chromatin remodeling, affects transcription of genes. In nucleosomes, DNA is wrapped around histone octamers consisting of two copies each of $\mathrm{H} 2 \mathrm{~A}, \mathrm{H} 2 \mathrm{~B}$, $\mathrm{H} 3$ and H4 (Kamakaka and Biggins, 2005). Post-translational modifications of histones as well as methylation of cytosine residues in DNA affect chromatin composition. The modifications of histones include methylation, acetylation, ubiquitination, and phosphorylation (Geiman and Robertson, 2002; Nowak and Corces, 2004). Usually, DNA methylation leads to suppression of transcriptional activity, whereas, acetylation of histones, especially in $\mathrm{H} 3$ and $\mathrm{H} 4$, activates transcription (Vaillant and Paszkowski, 2007). In contrast, methylation of histones can affect transcription both positively and negatively, depending on the histone protein and position of the modification (Zhang, 2008). Histone replacement, a process of substitution of canonical histones with histone variants, is also associated with chromatin remodeling (Kamakaka and Biggins, 2005; March-Diaz et al., 2008). Higher eukaryotes including plants possess machinery to initiate and maintain both DNA and histone modifications. Evidence suggests that both flowering and SAR are regulated by epigenetic modifications; interestingly, with machinery shared by both the pathways.

\section{Pathogen- and SA- Induced Histone Modification}

Expression of several SA responsive genes is epigenetically regulated. Exogenous application of benzothiadiazole (BTH), a chemical analog of SA and potential SAR inducer, induces accumulation of modified histones that favor transcription, such as acetylated histone 3 ( $\mathrm{H} 3 \mathrm{Ac})$, and di- and tri- methylated histone 3 at lysine 4 (H3K4me2 and $\mathrm{H} 3 \mathrm{~K} 4 \mathrm{me} 3)$ in the promoters of several WRKY genes, whose functions are associated with SAR activation (Jaskiewicz et al., 2011). Exogenous application of SA also induces such modifications in the PR-1 promoter (Mosher et al., 2006). During SAR activation upon primary infection, the systemic tissues undergo similar epigenetic modifications, which is associated with robust expression of these defense related genes during challenge inoculation (Conrath, 2011; Singh et al., 2014b). Under stress-free condition, SUPPRESSOR OF PR-1 INDUCIBLE 1 (SNI1), a negative regulator of SAR, is thought to contribute to maintaining the basal expression of $P R-1$ and $W R K Y$ genes by reducing these histones marks (Mosher et al., 2006).

\section{Histone Modifications; Flowering and SAR}

FLD codes for an Arabidopsis ortholog of human LYSINE SPECIFIC DEMETHYLASE 1 (LSD1; Liu et al., 2007). FLD, an approximately $96 \mathrm{KDa}$ protein contains a small DNA binding SWRIM domain, and a large polyamine oxidase (PAO) domain (He et al., 2003). Transcriptional co-repressor complexes containing PAO domains are one of the major regulators of gene expression in animals (Jepsen and Rosenfeld, 2002). LSD1 is a component of a co-repressor complex, with histone demethylase activity (Shi et al., 2004). The biochemical function of FLD has not been ascertained. However, the fld lossof-function mutants show increased occupancy of methylated $\mathrm{H} 3 \mathrm{~K} 4$ in FLC locus as might be expected based on its structural similarity to LSD1, which is a histone demethylase (Liu et al., 2007; Singh et al., 2014b). In addition, the FLC locus also shows increased accumulation of acetylated H3 in the fld mutant background, both of which support the observation of increased expression of FLC in fld mutants (He et al., 2003; Singh et al., 2014b). However, in contrast to the FLC locus, promoters of WRKY6 and WRKY29 genes show reduced accumulation of methylated H3K4 and acetylated H3 (Singh et al., 2014b). Nevertheless, experiments suggest that the histone demethylase activity of FLD is important for SAR activation and flowering. For example, exogenous application of histone demethylase inhibitor trans-2-phenylcyclopropylamine (2-PCPA) results in an fld lossof-function phenotype in terms of both flowering and SAR activation (Singh et al., 2014a). Application of 2-PCPA results in impairment of SAR activation, suppression of accumulation of methylated $\mathrm{H} 3 \mathrm{~K} 4$ in WRKY promoters and delays flowering (Singh et al., 2014a). FLD targets for SAR induction remain unidentified. It is postulated that the effect of FLD on histone modification of WRKY genes is indirect and may be mediated through other factors, functions of which are modulated by FLD (Singh et al., 2013, 2014a,b).

Histone deacetylases (HDACs) are often found in multiprotein co-repressor complexes. HISTONE DEACETYLASE 19 (HDA19) of Arabidopsis is a yeast REDUCED POTASSIUM DEFICIENCY 3 (RPD3)-like protein that affects both flowering and SAR (Zhou et al., 2005; Choi et al., 2012; Krogan et al., 2012; Wang et al., 2014). HDA19 interacts with LEUNIG/SEUSS co-repressor complex and negatively regulates expression of the floral patterning gene AGAMOUS (AG; Gonzalez et al., 2007). The hda19 mutant accumulates SA and has increased expression of SA-inducible genes such as EDS1, PAD4, ICS1 as well as $P R$ genes, providing resistance against $P$. syringae (Choi et al., 2012). HDA19, a putative corepressor has been found to directly associate with and deacetylate histones at the $P R-1$ and $P R-2$ promoters and repress their expression by modifying histones (Choi et al., 2012).

\section{Histone Replacement in SAR and Flowering}

The mutants that constitutively activate SAR, show disease resistance, accumulation of SA and expression of PR genes without pathogen challenge, and also often develop microscopic cell death (Jirage et al., 2001; Nandi et al., 2005; Swain et al., 2011). Substitution of canonical histone H2A with H2A.Z variant is a mechanism of chromatin remodeling that is associated with early flowering and activation of constitutive SAR. Replacement of histone $\mathrm{H} 2 \mathrm{~A}$ with $\mathrm{H} 2 \mathrm{~A} . \mathrm{Z}$ requires a multisubunit complex, SWI2/SNF2-RELATED 1 (SWR1) in yeast 
and SNF2-RELATED CBP ACTIVATOR PROTEIN (SRCAP) in humans (Krogan et al., 2003; Kobor et al., 2004; Mizuguchi et al., 2004). Arabidopsis proteins PHOTOPERIOD-INDEPENDENT EARLY FLOWERING 1 (PIE1), ACTIN-RELATED PROTEIN 6 and SERRATED LEAVES AND EARLY FLOWERING (SEF) are related to SWR1 and SRCAP protein complex components (Noh and Amasino, 2003; March-Diaz et al., 2007, 2008). The PIE/ARP6/SEF complex is functional equivalent of yeast SWRI1 complex, components of which are required for deposition of $\mathrm{H} 2 \mathrm{~A}$.Z variant in genes like FLC that negatively regulates flowering (Martin-Trillo et al., 2006; Deal et al., 2007; March-Diaz et al., 2007). Mutations in these genes result in down regulation of FLC and early flowering (Figure 3). Mutations in Arabidopsis HTA9 and HTA11 genes that code for H2A.Z also result in developmental abnormalities and early flowering (Figure 3), very similar to the mutants of PEI/ARP6/SEF complex (March-Diaz et al., 2008). The double mutant hta9hta11 shows reduction in FLC expression and concomitant induction of FT expression similar to sef and pie1 mutants (Amasino, 1996). As an interesting correlation between SAR and flowering, the pie1, sef, and hta9hta11 mutants show activation of constitutive SAR (March-Diaz et al., 2008). Consequently, the pie1, sef, and hta9hta11 mutants show spontaneous cell death, and support less bacterial growth than wild-type plants (March-Diaz et al., 2008). The pie1 mutants also show constitute activation of PR1, WRKY38 and WRKY18, expression of which are associated with SAR activation (Wang et al., 2006).

\section{Sumoylation Regulators Connect SAR and Flowering}

Ubiquitin and SMALL UBIQUITIN-LIKE MODIFIER (SUMO) attach to a wide range of proteins, and alter their function and longevity in cells (Miura et al., 2007). SUMO covalently attaches to lysine residues of target proteins through E3 SUMO ligase (Wilkinson and Henley, 2010). SUMO conjugation modifies the conformation of target proteins and influences their interaction with other proteins (Hickey et al., 2012). SUMO modifications have been implicated in many biological processes including, nutrition metabolism, abiotic stress response, flowering, and immunity (Miura et al., 2005; Catala et al., 2007; Lee et al., 2007a; Zhang et al., 2013a). Arabidopsis SIZ1 (AtSIZ1) is an ortholog of mammalian and yeast E3 SUMO ligase (Miura et al., 2005). AtSIZ1 negatively regulates SAR activation (Lee et al., 2007a). The mutants of AtSIZ1, show enhanced expression of PHYTOALEXIN DEFICIENT 4 (PAD4) and ENHANCED DISEASE SUSCEPTIBILITY 1 (EDS1) that positively regulate SA biosynthesis. The atsiz1 mutants also accumulate SA and SA-glucoside conjugates (SAG), express SAR marker PR-1 constitutively, and are resistant to pathogens. All these phenotypes of atsiz1 are dependent on SA accumulation, as NahG expression in the atsiz1 mutant background, abolishes all SARassociated responses (Lee et al., 2007a). As a very interesting cross-connection between SAR and flowering, it has been reported that AtSIZ1 promotes FLC expression and thereby negatively regulates the flowering transition (Figure 3; Jin et al., 2008).
Very recently, it has also been shown that AtSIZ1 physically interacts with FLC and influences its stability (Figure 3; Son et al., 2014).

Reversal of SUMO conjugation is carried out by SUMO protease. The early in short days 4 (esd4) mutant has a mutation in the SUMO protease and thus accumulates SUMO conjugates (Villajuana-Bonequi et al., 2014). Though, the exact cause of early flowering in esd4 mutant is not known, it is believed that physiological stress caused by hyper-accumulation of SUMO conjugates may result in early flowering. Interestingly, a genetic screen for suppressors of esd4, identified a mutant of the SA biosynthetic gene isochorismate synthase 1 (ICS1/SID2; Villajuana-Bonequi et al., 2014). Early flowering of esd4 is partially rescued by the reduced SA levels in the esd4 sid2 double mutant (VillajuanaBonequi et al., 2014). Thus early flowering in esd4 mutant is also associated with SA signaling activation, an integral event of SAR activation.

\section{Reverse Association between Flowering and SAR}

The studies described above, provided evidence to support the idea that the flowering and SAR signaling pathways are highly integrated. However, there are reports that contradict this idea. For example, the HOPW1-1-INTERACTING3 (WIN3; alias PBS3, GDG1, GH3.12) gene of Arabidopsis is a positive regulator for $\mathrm{SAR}$ and negative regulator of flowering (Wang et al., 2011). The WIN3 gene product codes for an enzyme that conjugates aminoacids to 4-aminobenzoate or 4hydroxybenzoate; a process which is required for SA biosynthesis (Okrent et al., 2009). WIN3 expression is induced by $\mathrm{SA}$, and its function is needed for pathogenesis associated SA responses (Nobuta et al., 2007; Wang et al., 2011). However, mutation in WIN3 results in early flowering under long-day conditions (Lee et al., 2007b; Wang et al., 2011). The reverseassociation is also observed in plants undergoing the shade avoidance response. Since plants absorb more red than far-red light, the red:far-red ratio gets reduced under dense vegetation. The reduced red:far-red ratio enhances early flowering in Arabidopsis, a component of the shade-avoidance response (Halliday et al., 1994, 2003). In contrast, plants grown in low red:far-red ratio exhibit compromised defense response in the form of reduced SA dependent PR1 and WRKY expression (de Wit et al., 2013). The lack of an association between SAR and flowering is observed in mutants such as $n p r 1$ and $s f d 1$, which are defective in SAR but not in flowering. Therefore, these reports indicate that the SAR and flowering pathways are genetically separable, even though they share common inducers, such as SA.

\section{Conclusion}

It appears that some of the molecular machinery that regulates flowering time is shared by the SAR activation processes in plants. A number of studies suggest that retention of infection 
memory in plants is mostly mediated through epigenetic mechanisms. While generating resistance against invading pathogens, plant tissues generate signals that are capable of long distance transport to carry infection information to distant tissues. Upon arrival in distal tissues, mobile signals are perceived, leading to biosynthesis and accumulation of SA, which is required for SAR activation as well as the floral transition. In addition, the perception of mobile signals also initiates epigenetic modification of certain key genes which contribute to infection memory development and SAR associated priming defense responses. Alteration of histone methylation and acetylation, and histone replacement influence flowering and SAR. Suppression of SAR in healthy plants and flowering during vegetative growth, are highly important for overall growth, development and productivity of plants. Emerging data strongly suggest

\section{References}

Amasino, R. M. (1996). Control of flowering time in plants. Curr. Opin. Genet. Dev. 6, 480-487. doi: 10.1016/S0959-437X(96)80071-2

Aukerman, M. J., and Amasino, R. M. (1996). Molecular genetic analysis of flowering time in Arabidopsis. Semin. Cell Dev. Biol. 7, 427-433. doi: 10.1006/scdb. 1996.0053

Ballare, C. L., Mazza, C. A., Austin, A. T., and Pierik, R. (2012). Canopy light and plant health. Plant Physiol. 160, 145-155. doi: 10.1104/pp.112. 200733

Caruso, F. L., and Kuc, J. (1977). Protection of watermelon and muskmelon against Colletotrichum lagenarium by Colletotrichum lagenarium. Phytopathology 67, 1285-1289. doi: 10.1094/Phyto-67-1285

Catala, R., Ouyang, J., Abreu, I. A., Hu, Y., Seo, H., Zhang, X., et al. (2007). The Arabidopsis E3 SUMO ligase SIZ1 regulates plant growth and drought responses. Plant Cell 19, 2952-2966. doi: 10.1105/tpc.106.049981

Chailakhyan, M. K. (1936). New facts in support of the hormonal theory of plant development. C. R. Acad. Sci. URSS 13, 79-83.

Champigny, M. J., Isaacs, M., Carella, P., Faubert, J., Fobert, P. R., and Cameron, R. K. (2013). Long distance movement of DIR1 and investigation of the role of DIR1-like during systemic acquired resistance in Arabidopsis. Front. Plant. Sci. 4:230. doi: 10.3389/fpls.2013.00230

Chanda, B., Xia, Y., Mandal, M. K., Yu, K., Sekine, K. T., Gao, Q. M., et al. (2011). Glycerol-3-phosphate is a critical mobile inducer of systemic immunity in plants. Nat. Genet. 43, 421-427. doi: 10.1038/ng.798

Chandra-Shekara, A. C., Gupte, M., Navarre, D., Raina, S., Raina, R., Klessig, D., et al. (2006). Light-dependent hypersensitive response and resistance signaling against turnip crinkle virus in Arabidopsis. Plant J. 45, 320-334. doi: 10.1111/j.1365-313X.2005.02618.x

Chaturvedi, R., Krothapalli, K., Makandar, R., Nandi, A., Sparks, A. A., Roth, M. R., et al. (2008). Plastid omega3-fatty acid desaturase-dependent accumulation of a systemic acquired resistance inducing activity in petiole exudates of Arabidopsis thaliana is independent of jasmonic acid. Plant J. 54, 106-117. doi: 10.1111/j.1365-313X.2007.03400.x

Chaturvedi, R., Venables, B., Petros, R. A., Nalam, V., Li, M., Wang, X., et al. (2012). An abietane diterpenoid is a potent activator of systemic acquired resistance. Plant J. 71, 161-172. doi: 10.1111/j.1365-313X.2012.04981.x

Chinchilla, D., Shan, L., He, P., De Vries, S., and Kemmerling, B. (2009). One for all: the receptor-associated kinase BAK1. Trends Plant Sci. 14, 535-541. doi: 10.1016/j.tplants.2009.08.002

Choi, S. M., Song, H. R., Han, S. K., Han, M., Kim, C. Y., Park, J., et al. (2012). HDA19 is required for the repression of salicylic acid biosynthesis and salicylic acid-mediated defense responses in Arabidopsis. Plant J. 71, 135-146. doi: 10.1111/j.1365-313X.2012.04977.x

Cleland, C. F., and Ajami, A. (1974). Identification of the flower-inducing factor isolated from aphid honeydew as being salicylic acid. Plant Physiol. 54, 904-906. doi: 10.1104/pp.54.6.904 common genetic and epigenetic regulators for flowering and SAR.

\section{Author contributions}

Both the authors equally contributed to the manuscript.

\section{Acknowledgments}

We acknowledge Supriya Chakraborty for critical reading of the manuscript. This work is supported by Department of Biotechnology (DBT grant No. BT/PR14656/BRB/10/864/2010) to AN and ICMR fellowship to ZB.

Clouse, S. D. (2011). Brassinosteroid signal transduction: from receptor kinase activation to transcriptional networks regulating plant development. Plant Cell 23 1219-1230. doi: 10.1105/tpc.111.084475

Conrath, U. (2011). Molecular aspects of defence priming. Trends Plant Sci. 16, 524-531. doi: 10.1016/j.tplants.2011.06.004

Corbesier, L., Vincent, C., Jang, S., Fornara, F., Fan, Q., Searle, I., et al. (2007). FT protein movement contributes to long-distance signaling in floral induction of Arabidopsis. Science 316, 1030-1033. doi: 10.1126/science. 1141752

Deal, R. B., Topp, C. N., Mckinney, E. C., and Meagher, R. B. (2007). Repression of flowering in Arabidopsis requires activation of FLOWERING LOCUS C expression by the histone variant H2A.Z. Plant Cell 19, 74-83. doi: 10.1105/tpc.106.048447

Dempsey, D. A., and Klessig, D. F. (2012). SOS - too many signals for systemic acquired resistance? Trends Plant Sci. 17, 538-545. doi: 10.1016/j.tplants.2012.05.011

de Wit, M., Spoel, S. H., Sanchez-Perez, G. F., Gommers, C. M., Pieterse, C. M., Voesenek, L. A., et al. (2013). Perception of low red:far-red ratio compromises both salicylic acid- and jasmonic acid-dependent pathogen defences in Arabidopsis. Plant J. 75, 90-103. doi: 10.1111/tpj.12203

Dong, X. (2004). NPR1, all things considered. Curr. Opin. Plant Biol. 7, 547-552. doi: $10.1016 /$ j.pbi.2004.07.005

Durrant, W. E., and Dong, X. (2004). Systemic acquired resistance. Annu. Rev. Phytopathol. 42, 185-209. doi: 10.1146/annurev.phyto.42.040803.140421

Eulgem, T., Tsuchiya, T., Wang, X. J., Beasley, B., Cuzick, A., Tor, M., et al. (2007). EDM2 is required for RPP7-dependent disease resistance in Arabidopsis and affects RPP7 transcript levels. Plant J. 49, 829-839. doi: 10.1111/j.1365313X.2006.02999.x

Fragniere, C., Serrano, M., Abou-Mansour, E., Metraux, J. P., and L'haridon, F. (2011). Salicylic acid and its location in response to biotic and abiotic stress. FEBS Lett. 585, 1847-1852. doi: 10.1016/j.febslet.2011.04.039

Fu, Z. Q., and Dong, X. (2013). Systemic acquired resistance: turning local infection into global defense. Annu. Rev. Plant Biol. 64, 839-863. doi: 10.1146/annurevarplant-042811-105606

Fujioka, S., Sakurai, A., Yamaguchi, I., Murofushi, N., Takahashi, N., Kaihara, S., et al. (1987). Isolation and identification of L-Pipecolic acid and nicotinamide as flower-inducing substances in Lemna. Plant Cell Physiol. 28, 995-1003.

Gaffney, T., Friedrich, L., Vernooij, B., Negrotto, D., Nye, G., Uknes, S., et al. (1993). Requirement of salicylic acid for the induction of systemic acquired resistance. Science 261, 754-756. doi: 10.1126/science.261. 5122.754

Geiman, T. M., and Robertson, K. D. (2002). Chromatin remodeling, histone modifications, and DNA methylation-how does it all fit together? J. Cell Biochem. 87, 117-125. doi: $10.1002 /$ jcb. 10286

Gonzalez, D., Bowen, A. J., Carroll, T. S., and Conlan, R. S. (2007). The transcription corepressor LEUNIG interacts with the histone deacetylase 
HDA19 and mediator components MED14 (SWP) and CDK8 (HEN3) to repress transcription. Mol. Cell. Biol. 27, 5306-5315. doi: 10.1128/MCB. 01912-1916

Griebel, T., and Zeier, J. (2008). Light regulation and daytime dependency of inducible plant defenses in Arabidopsis: phytochrome signaling controls systemic acquired resistance rather than local defense. Plant Physiol. 147, 790-801. doi: 10.1104/pp.108.119503

Guedes, M. E. M., Richmond, S., and Kuc, J. (1980). Induced systemic resistance to anthracnose in cucumber as influenced by the location of the inducer inoculation with Colletotrichum lagenarium and the onset of flowering and fruiting physiol. Plant Pathol. 17, 229-233.

Halliday, K. J., Koornneef, M., and Whitelam, G. C. (1994). Phytochrome B and at least one other phytochrome mediate the accelerated flowering response of Arabidopsis thaliana L. to low Red/Far-Red ratio. Plant Physiol. 104, 1311-1315.

Halliday, K. J., Salter, M. G., Thingnaes, E., and Whitelam, G. C. (2003). Phytochrome control of flowering is temperature sensitive and correlates with expression of the floral integrator FT. Plant J. 33, 875-885. doi: 10.1046/j.1365313X.2003.01674.X

He, Y., and Amasino, R. M. (2005). Role of chromatin modification in floweringtime control. Trends Plant Sci. 10, 30-35. doi: 10.1016/j.tplants.2004.11.003

He, Y. H., Michaels, S. D., and Amasino, R. M. (2003). Regulation of flowering time by histone acetylation in Arabidopsis. Science 302, 1751-1754. doi: 10.1126/science.1091109

Helliwell, C. A., Wood, C. C., Robertson, M., James Peacock, W., and Dennis, E. S. (2006). The Arabidopsis FLC protein interacts directly in vivo with SOC1 and FT chromatin and is part of a high-molecular-weight protein complex. Plant J. 46, 183-192. doi: 10.1111/j.1365-313X.2006.02686.x

Henderson, I. R., and Dean, C. (2004). Control of Arabidopsis flowering: the chill before the bloom. Development 131, 3829-3838. doi: 10.1242/dev.01294

Hickey, C. M., Wilson, N. R., and Hochstrasser, M. (2012). Function and regulation of SUMO proteases. Nat. Rev. Mol. Cell Biol. 13, 755-766. doi: 10.1038/nrm3478

Iriti, M., and Faoro, F. (2007). Review of innate and specific immunity in plants and animals. Mycopathologia 164, 57-64. doi: 10.1007/s11046-007-9026-9027

Islam, S. Z., Babadoost, M., Bekal, S., and Lambert, K. (2008). Red Light-induced systemic disease resistance against Root-knot nematode Meloidogyne javanica and Pseudomonas syringae pv. tomato DC 3000. J. Phytopathol. 156, 708-714. doi: 10.1111/j.1439-0434.2008.01435.x

Jaskiewicz, M., Conrath, U., and Peterhansel, C. (2011). Chromatin modification acts as a memory for systemic acquired resistance in the plant stress response. EMBO Rep. 12, 50-55. doi: 10.1038/embor.2010.186

Jepsen, K., and Rosenfeld, M. G. (2002). Biological roles and mechanistic actions of co-repressor complexes. J. Cell Sci. 115, 689-698.

Jin, J. B., Jin, Y. H., Lee, J., Miura, K., Yoo, C. Y., Kim, W. Y., et al. (2008). The SUMO E3 ligase, AtSIZ1, regulates flowering by controlling a salicylic acidmediated floral promotion pathway and through affects on FLC chromatin structure. Plant J. 53, 530-540. doi: 10.1111/j.1365-313X.2007.03359.x

Jirage, D., Zhou, N., Cooper, B., Clarke, J. D., Dong, X., and Glazebrook, J. (2001). Constitutive salicylic acid-dependent signaling in cpr1 and cpr6 mutants requires PAD4. Plant J. 26, 395-407. doi: 10.1046/j.1365-313X.2001.26 41040.x

Jones, J. D., and Dangl, J. L. (2006). The plant immune system. Nature 444, 323-329. doi: 10.1038/nature05286

Jung, H. W., Tschaplinski, T. J., Wang, L., Glazebrook, J., and Greenberg, J. T. (2009). Priming in systemic plant immunity. Science 324, 89-91. doi: 10.1126/science. 1170025

Kamakaka, R. T., and Biggins, S. (2005). Histone variants: deviants? Genes Dev. 19, 295-310. doi: 10.1101/gad.1272805

Kangasjarvi, S., Neukermans, J., Li, S., Aro, E. M., and Noctor, G. (2012). Photosynthesis, photorespiration, and light signalling in defence responses. J. Exp. Bot. 63, 1619-1636. doi: 10.1093/jxb/err402

Khurana, J. P., and Cleland, C. F. (1992). Role of salicylic acid and benzoic acid in flowering of a Photoperiod-Insensitive strain, Lemna paucicostata LP6. Plant Physiol. 100, 1541-1546. doi: 10.1104/pp.100.3.1541

Kim, T. W., Guan, S., Burlingame, A. L., and Wang, Z. Y. (2011). The CDG1 kinase mediates brassinosteroid signal transduction from BRI1 receptor kinase to BSU1 phosphatase and GSK3-like kinase BIN2. Mol. Cell 43, 561-571. doi: 10.1016/j.molcel.2011.05.037
Kinkema, M., Fan, W., and Dong, X. (2000). Nuclear localization of NPR1 is required for activation of PR gene expression. Plant Cell 12, 2339-2350. doi: 10.1105/tpc.12.12.2339

Knott, J. E. (1934). Effect of localized photoperiod on spinach. Proc. Am. Soc. Hortic. Sci. 31, 152-154.

Kobor, M. S., Venkatasubrahmanyam, S., Meneghini, M. D., Gin, J. W., Jennings, J. L., Link, A. J., et al. (2004). A protein complex containing the conserved Swi2/Snf2-related ATPase Swrlp deposits histone variant H2A.Z into euchromatin. PLoS Biol. 2:E131. doi: 10.1371/journal.pbio.0020131

Krogan, N. J., Keogh, M. C., Datta, N., Sawa, C., Ryan, O. W., Ding, H., et al. (2003). A Snf2 family ATPase complex required for recruitment of the histone H2A variant Htz1. Mol. Cell 12, 1565-1576. doi: 10.1016/S1097-2765(03) 00497-0

Krogan, N. T., Hogan, K., and Long, J. A. (2012). APETALA2 negatively regulates multiple floral organ identity genes in Arabidopsis by recruiting the co-repressor TOPLESS and the histone deacetylase HDA19. Development 139, 4180-4190. doi: 10.1242/dev.085407 dev.085407

Kuc, J., and Richmond, S. (1977). Aspects of protection of cucumber against Colletotrichum lagenarium by Colletotrichum lagenarium. Phytopathology 67, 533-536. doi: 10.1094/Phyto-67-533

Lawton, K. A., Friedrich, L., Hunt, M., Weymann, K., Delaney, T., Kessmann, H., et al. (1996). Benzothiadiazole induces disease resistance in Arabidopsis by activation of the systemic acquired resistance signal transduction pathway. Plant J. 10, 71-82. doi: 10.1046/j.1365-313X.1996.10010071.x

Lee, J., Nam, J., Park, H. C., Na, G., Miura, K., Jin, J. B., et al. (2007a). Salicylic acidmediated innate immunity in Arabidopsis is regulated by SIZ1 SUMO E3 ligase. Plant J. 49, 79-90. doi: 10.1111/j.1365-313X.2006.02947.x

Lee, M. W., Lu, H., Jung, H. W., and Greenberg, J. T. (2007b). A key role for the Arabidopsis WIN3 protein in disease resistance triggered by Pseudomonas syringae that secrete AvrRpt2. Mol. Plant Microbe Interact. 20, 1192-1200. doi: 10.1094/MPMI-20-10-1192

Li, C., Luo, L., Fu, Q., Niu, L., and Xu, Z. F. (2014). Isolation and functional characterization of JcFT, a FLOWERING LOCUS T (FT) homologous gene from the biofuel plant Jatropha curcas. BMC Plant Biol. 14:125. doi: 10.1186/1471-222914-125

Lin, W., Lu, D., Gao, X., Jiang, S., Ma, X., Wang, Z., et al. (2013). Inverse modulation of plant immune and brassinosteroid signaling pathways by the receptorlike cytoplasmic kinase BIK1. Proc. Natl. Acad. Sci. U.S.A. 110, 12114-12119. doi: 10.1073/pnas.1302154110

Liu, F., Quesada, V., Crevillen, P., Baurle, I., Swiezewski, S., and Dean, C. (2007). The Arabidopsis RNA-binding protein FCA requires a lysine-specific demethylase 1 homolog to downregulate FLC. Mol. Cell 28, 398-407. doi: 10.1016/j.molcel.2007.10.018

Lu, D., Wu, S., Gao, X., Zhang, Y., Shan, L., and He, P. (2010). A receptor-like cytoplasmic kinase, BIK1, associates with a flagellin receptor complex to initiate plant innate immunity. Proc. Natl. Acad. Sci. U.S.A. 107, 496-501. doi: 10.1073/pnas.0909705107

Luna, E., Bruce, T. J., Roberts, M. R., Flors, V., and Ton, J. (2012). Nextgeneration systemic acquired resistance. Plant Physiol. 158, 844-853. doi: $10.1104 /$ pp.111.187468

March-Diaz, R., Garcia-Dominguez, M., Florencio, F. J., and Reyes, J. C. (2007). SEF, a new protein required for flowering repression in Arabidopsis, interacts with PIE1 and ARP6. Plant Physiol. 143, 893-901. doi: 10.1104/pp.106.092270

March-Diaz, R., Garcia-Dominguez, M., Lozano-Juste, J., Leon, J., Florencio, F. J., and Reyes, J. C. (2008). Histone H2A.Z and homologues of components of the SWR1 complex are required to control immunity in Arabidopsis. Plant J. 53, 475-487. doi: 10.1111/j.1365-313X.2007.03361.x

Martin-Trillo, M., Lázaro, A., Poethig, R. S., Gómez-Mena, C., Piñeiro, M. A., Martinez-Zapater, J. M., et al. (2006). EARLY IN SHORT DAYS 1 (ESD1) encodes ACTIN-RELATED PROTEIN 6 (AtARP6), a putative component of chromatin remodelling complexes that positively regulates FLC accumulation in Arabidopsis. Development 133, 1241-1252. doi: 10.1242/dev.02301

Martinez, C., Pons, E., Prats, G., and Leon, J. (2004). Salicylic acid regulates flowering time and links defence responses and reproductive development. Plant J. 37, 209-217. doi: 10.1046/j.1365-313X.2003.01954.x

Metraux, J. P., Signer, H., Ryals, J., Ward, E., Wyss-Benz, M., Gaudin, J., et al. (1990). Increase in salicylic acid at the onset of systemic acquired resistance in cucumber. Science 250, 1004-1006. doi: 10.1126/science.250.4983.1004 
Michaels, S. D., and Amasino, R. M. (1999). FLOWERING LOCUS C encodes a novel MADS domain protein that acts as a repressor of flowering. Plant Cell 11, 949-956. doi: 10.1105/tpc.11.5.949

Miura, K., Jin, J. B., and Hasegawa, P. M. (2007). Sumoylation, a post-translational regulatory process in plants. Curr. Opin. Plant Biol. 10, 495-502. doi: 10.1016/j.pbi.2007.07.002

Miura, K., Rus, A., Sharkhuu, A., Yokoi, S., Karthikeyan, A. S., Raghothama, K. G., et al. (2005). The Arabidopsis SUMO E3 ligase SIZ1 controls phosphate deficiency responses. Proc. Natl. Acad. Sci. U.S.A. 102, 7760-7765. doi: 10.1073/pnas.0500778102

Mizuguchi, G., Shen, X., Landry, J., Wu, W. H., Sen, S., and Wu, C. (2004). ATP-driven exchange of histone $\mathrm{H} 2 \mathrm{AZ}$ variant catalyzed by SWR1 chromatin remodeling complex. Science 303, 343-348. doi: 10.1126/science.1090701

Mosher, R. A., Durrant, W. E., Wang, D., Song, J., and Dong, X. (2006). A comprehensive structure-function analysis of Arabidopsis SNI1 defines essential regions and transcriptional repressor activity. Plant Cell 18, 1750-1765. doi: $10.1105 /$ tpc. 105.039677

Nandi, A., Moeder, W., Kachroo, P., Klessig, D. F., and Shah, J. (2005). Arabidopsis ssi2-conferred susceptibility to Botrytis cinerea is dependent on EDS5 and PAD4. Mol. Plant Microbe Interact. 18, 363-370. doi: 10.1094/MPMI-18-0363

Nandi, A., Welti, R., and Shah, J. (2004). The Arabidopsis thaliana dihydroxyacetone phosphate reductase gene SUPPRESSSOR OF FATTY ACID DESATURASE DEFICIENCY1 is required for glycerolipid metabolism and for the activation of systemic acquired resistance. Plant Cell 16, 465-477. doi: 10.1105/tpc. 016907

Navarova, H., Bernsdorff, F., Doring, A. C., and Zeier, J. (2012). Pipecolic acid, an endogenous mediator of defense amplification and priming, is a critical regulator of inducible plant immunity. Plant Cell 24, 5123-5141. doi: 10.1105/tpc.112.103564

Nimchuk, Z., Eulgem, T., Holt, B. F. III, and Dangl, J. L. (2003). Recognition and response in the plant immune system. Annu. Rev. Genet. 37, 579-609. doi: 10.1146/annurev.genet.37.110801.142628

Nobuta, K., Okrent, R. A., Stoutemyer, M., Rodibaugh, N., Kempema, L., Wildermuth, M. C., et al. (2007). The GH3 acyl adenylase family member PBS3 regulates salicylic acid-dependent defense responses in Arabidopsis. Plant Physiol. 144, 1144-1156. doi: 10.1104/pp.107.097691

Noh, Y. S., and Amasino, R. M. (2003). PIE1, an ISWI family gene, is required for FLC activation and floral repression in Arabidopsis. Plant Cell 15, 1671-1682. doi: $10.1105 /$ tpc. 012161

Nowak, S. J., and Corces, V. G. (2004). Phosphorylation of histone H3: a balancing act between chromosome condensation and transcriptional activation. Trends Genet. 20, 214-220. doi: 10.1016/j.tig.2004.02.007

Okrent, R. A., Brooks, M. D., and Wildermuth, M. C. (2009). Arabidopsis GH3.12 (PBS3) conjugates amino acids to 4 -substituted benzoates and is inhibited by salicylate. J. Biol. Chem. 284, 9742-9754. doi: 10.1074/jbc.M806662200

Ross, A. F. (1961). Systemic acquired resistance induced by localized virus infections in plants. Virology 14, 340-358. doi: 10.1016/0042-6822(61)90319-1

Roux, M., Schwessinger, B., Albrecht, C., Chinchilla, D., Jones, A., Holton, N., et al. (2011). The Arabidopsis leucine-rich repeat receptor-like kinases BAK1/SERK3 and BKK1/SERK4 are required for innate immunity to hemibiotrophic and biotrophic pathogens. Plant Cell 23, 2440-2455. doi: 10.1105/tpc.111.084301

Ryals, J. A., Neuenschwander, U. H., Willits, M. G., Molina, A., Steiner, H. Y., and Hunt, M. D. (1996). Systemic acquired resistance. Plant Cell 8, 1809-1819. doi: 10.1105/tpc.8.10.1809

Sano, S., Aoyama, M., Nakai, K., Shimotani, K., Yamasaki, K., Sato, M. H., et al. (2014). Light-dependent expression of flg22-induced defense genes in Arabidopsis. Front. Plant Sci. 5:531. doi: 10.3389/fpls.2014.00531

Schwessinger, B., and Ronald, P. C. (2012). Plant innate immunity: perception of conserved microbial signatures. Annu. Rev. Plant Biol. 63, 451-482. doi: 10.1146/annurev-arplant-042811-105518

Shi, Y., Lan, F., Matson, C., Mulligan, P., Whetstine, J. R., Cole, P. A., et al. (2004). Histone demethylation mediated by the nuclear amine oxidase homolog LSD1. Cell 119, 941-953. doi: 10.1016/j.cell.2004.12.012

Simpson, G. G., and Dean, C. (2002). Arabidopsis, the rosetta stone of flowering time? Science 296, 285-289. doi: 10.1126/science.296.5566.285 296/5566/285

Simpson, G. G., Gendall, A. R., and Dean, C. (1999). When to switch to flowering. Annu. Rev. Cell Dev. Biol. 15, 519-550. doi: 10.1146/annurev.cellbio. 15.1.519
Singh, V., Banday, Z. Z., and Nandi, A. K. (2014a). Exogenous application of histone demethylase inhibitor trans-2-phenylcyclopropylamine mimics FLD lossof-function phenotype in terms of systemic acquired resistance in Arabidopsis thaliana. Plant Signal. Behav. doi: 10.4161/psb.29658 [Epub ahead of print].

Singh, V., Roy, S., Singh, D., and Nandi, A. K. (2014b). Arabidopsis flowering locus $\mathrm{D}$ influences systemic-acquired-resistance- induced expression and histone modifications of WRKY genes. J. Biosci. 39, 119-126. doi: 10.1007/s12038-0139407-7

Singh, V., Roy, S., Giri, M. K., Chaturvedi, R., Chowdhury, Z., Shah, J., et al. (2013). Arabidopsis thaliana FLOWERING LOCUS D is required for systemic acquired resistance. Mol. Plant Microbe Interact. 26, 1079-1088. doi: 10.1094/MPMI-04-13-0096-R

Slaughter, A., Daniel, X., Flors, V., Luna, E., Hohn, B., and Mauch-Mani, B. (2012). Descendants of primed Arabidopsis plants exhibit resistance to biotic stress. Plant Physiol. 158, 835-843. doi: 10.1104/pp.111.191593 pp.111.191593

Smith, H. (2000). Phytochromes and light signal perception by plantsan emerging synthesis. Nature 407, 585-591. doi: 10.1038/350 36500

Son, G. H., Park, B. S., Song, J. T., and Seo, H. S. (2014). FLC-mediated flowering repression is positively regulated by sumoylation. J. Exp. Bot. 65, 339-351. doi: $10.1093 / \mathrm{jxb} / \mathrm{ert} 383$ ert383

Sticher, L., Mauch-Mani, B., and Metraux, J. P. (1997). Systemic acquired resistance. Аnnu. Rev. Phytopathol. 35, 235-270. doi: 10.1146/annurev.phyto.35.1.235

Suarez-Lopez, P., Wheatley, K., Robson, F., Onouchi, H., Valverde, F., and Coupland, G. (2001). CONSTANS mediates between the circadian clock and the control of flowering in Arabidopsis. Nature 410, 1116-1120. doi: $10.1038 / 35074138$

Sun, Y., Li, L., Macho, A. P., Han, Z., Hu, Z., Zipfel, C., et al. (2013). Structural basis for flg22-induced activation of the Arabidopsis FLS2-BAK1 immune complex. Science 342, 624-628. doi: 10.1126/science.1243825

Swain, S., Roy, S., Shah, J., Van Wees, S., Pieterse, C. M., and Nandi, A. K. (2011). Arabidopsis thaliana cdd 1 mutant uncouples the constitutive activation of salicylic acid signalling from growth defects. Mol. Plant Pathol. 12, 855-865. doi: 10.1111/j.1364-3703.2011.00717.x

Tamaki, S., Matsuo, S., Wong, H. L., Yokoi, S., and Shimamoto, K. (2007). Hd3a protein is a mobile flowering signal in rice. Science 316, 1033-1036. doi: $10.1126 /$ science. 1141753

Tang, W., Kim, T. W., Oses-Prieto, J. A., Sun, Y., Deng, Z., Zhu, S., et al. (2008). BSKs mediate signal transduction from the receptor kinase BRI1 in Arabidopsis. Science 321, 557-560. doi: 10.1126/science.1156973

Tang, W., Yuan, M., Wang, R., Yang, Y., Wang, C., Oses-Prieto, J. A., et al. (2011). PP2A activates brassinosteroid-responsive gene expression and plant growth by dephosphorylating BZR1. Nat. Cell Biol. 13, 124-131. doi: 10.1038/ncb2151

Tsuchiya, T., and Eulgem, T. (2010). The Arabidopsis defense component EDM2 affects the floral transition in an FLC-dependent manner. Plant J. 62, 518-528. doi: 10.1111/j.1365-313X.2010.04169.x TPJ4169

Tuzun, S., and Kuc, J. (1985). Movement of a factor in tobacco infected with Peronospora tabacina Adam which systemically protect against blue mold. Physiol. Plant Pathol. 26, 321-330. doi: 10.1016/0048-4059(85)90007-4

Vaillant, I., and Paszkowski, J. (2007). Role of histone and DNA methylation in gene regulation. Curr. Opin. Plant Biol. 10, 528-533. doi: 10.1016/j.pbi.2007. 06.008

van Loon, L. C., Rep, M., and Pieterse, C. M. (2006). Significance of inducible defense-related proteins in infected plants. Annu. Rev. Phytopathol. 44, 135162. doi: 10.1146/annurev.phyto.44.070505.143425.

Varkonyi-Gasic, E., Moss, S. M., Voogd, C., Wang, T., Putterill, J., and Hellens, R. P. (2013). Homologs of FT, CEN and FD respond to developmental and environmental signals affecting growth and flowering in the perennial vine kiwifruit. New Phytol. 198, 732-746. doi: 10.1111/nph.12162

Verhage, A., Van Wees, S. C., and Pieterse, C. M. (2010). Plant immunity: it's the hormones talking, but what do they say? Plant Physiol. 154, 536-540. doi: 10.1104/pp.110.161570

Villajuana-Bonequi, M., Elrouby, N., Nordstrom, K., Griebel, T., Bachmair, A., and Coupland, G. (2014). Elevated salicylic acid levels conferred by increased expression of ISOCHORISMATE SYNTHASE 1 contribute to hyperaccumulation of SUMO1 conjugates in the Arabidopsis mutant early in short days 4. Plant J. 79, 206-219. doi: 10.1111/tpj.12549 
Vlot, A. C., Klessig, D. F., and Park, S. W. (2008). Systemic acquired resistance: the elusive signal(s). Curr. Opin. Plant Biol. 11, 436-442. doi: 10.1016/j.pbi.2008.05.003

Wada, K. C., Mizuuchi, K., Koshio, A., Kaneko, K., Mitsui, T., and Takeno, K. (2014). Stress enhances the gene expression and enzyme activity of phenylalanine ammonia-lyase and the endogenous content of salicylic acid to induce flowering in pharbitis. J. Plant Physiol. 171, 895-902. doi: 10.1016/j.jplph.2014.03.008

Wang, D., Amornsiripanitch, N., and Dong, X. (2006). A genomic approach to identify regulatory nodes in the transcriptional network of systemic acquired resistance in plants. PLoS Pathog. 2:e123. doi: 10.1371/journal.ppat. 0020123

Wang, G. F., Seabolt, S., Hamdoun, S., Ng, G., Park, J., and Lu, H. (2011). Multiple roles of WIN3 in regulating disease resistance, cell death, and flowering time in Arabidopsis. Plant Physiol. 156, 1508-1519. doi: 10.1104/pp.111. 176776

Wang, H., Jiang, Y. P., Yu, H. J., Xia, X. J., Shi, K., Zhou, Y. H., et al. (2010). Light quality affects incidence of powdery mildew, expression of defence-related genes and associated metabolism in cucumber plants. Eur. J. Plant Pathol. 127, 125-135. doi: 10.1007/s10658-009-9577-9571

Wang, Z., Cao, H., Chen, F., and Liu, Y. (2014). The roles of histone acetylation in seed performance and plant development. Plant Physiol. Biochem. 84C, 125-133. doi: 10.1016/j.plaphy.2014.09.010

Ward, E. R., Uknes, S. J., Williams, S. C., Dincher, S. S., Wiederhold, D. L., Alexander, D. C., et al. (1991). Coordinate gene activity in response to agents that induce systemic acquired resistance. Plant Cell 3, 1085-1094. doi: $10.1105 /$ tpc.3.10.1085

Wilkinson, K. A., and Henley, J. M. (2010). Mechanisms, regulation and consequences of protein SUMOylation. Biochem. J. 428, 133-145. doi: 10.1042/BJ20100158

Wu, Y., Zhang, D., Chu, J. Y., Boyle, P., Wang, Y., Brindle, I. D., et al. (2012). The Arabidopsis NPR1 protein is a receptor for the plant defense hormone salicylic acid. Cell Rep. 1, 639-647. doi: 10.1016/j.celrep.2012.05.008

Yalpani, N., Silverman, P., Wilson, T. M., Kleier, D. A., and Raskin, I. (1991). Salicylic acid is a systemic signal and an inducer of pathogenesis-related proteins in virus-infected tobacco. Plant Cell 3, 809-818. doi: 10.1105/tpc.3. 8.809
Yang, C. J., Zhang, C., Lu, Y. N., Jin, J. Q., and Wang, X. L. (2011). The mechanisms of brassinosteroids' action: from signal transduction to plant development. $\mathrm{Mol}$. Plant 4, 588-600. doi: 10.1093/mp/ssr020

Zeevaart, J. A. (2006). Florigen coming of age after 70 years. Plant Cell 18, 1783-1789. doi: 10.1105/tpc.106.043513

Zeier, J., Pink, B., Mueller, M. J., and Berger, S. (2004). Light conditions influence specific defence responses in incompatible plant-pathogen interactions: uncoupling systemic resistance from salicylic acid and PR-1 accumulation. Planta 219, 673-683. doi: 10.1007/s00425-004-1272-z

Zhang, J., Li, W., Xiang, T., Liu, Z., Laluk, K., Ding, X., et al. (2010). Receptor-like cytoplasmic kinases integrate signaling from multiple plant immune receptors and are targeted by a Pseudomonas syringae effector. Cell Host Microbe 7, 290-301. doi: 10.1016/j.chom.2010.03.007

Zhang, S., Qi, Y., Liu, M., and Yang, C. (2013a). SUMO E3 ligase AtMMS21 regulates drought tolerance in Arabidopsis thaliana(F). J. Integr. Plant Biol. 55, 83-95. doi: 10.1111/jipb.12024

Zhang, Y., Li, B., Xu, Y., Li, H., Li, S., Zhang, D., et al. (2013b). The cyclophilin CYP20-2 modulates the conformation of BRASSINAZOLE-RESISTANT1, which binds the promoter of FLOWERING LOCUS D to regulate flowering in Arabidopsis. Plant Cell 25, 2504-2521. doi: 10.1105/tpc.113.110296

Zhang, X. (2008). The epigenetic landscape of plants. Science 320, 489-492. doi: $10.1126 /$ science. 1153996

Zhou, C., Zhang, L., Duan, J., Miki, B., and Wu, K. (2005). HISTONE DEACETYLASE19 is involved in jasmonic acid and ethylene signaling of pathogen response in Arabidopsis. Plant Cell 17, 1196-1204. doi: 10.1105/tpc.104.028514

Conflict of Interest Statement: The authors declare that the research was conducted in the absence of any commercial or financial relationships that could be construed as a potential conflict of interest.

Copyright (c) 2015 Banday and Nandi. This is an open-access article distributed under the terms of the Creative Commons Attribution License (CC BY). The use, distribution or reproduction in other forums is permitted, provided the original author(s) or licensor are credited and that the original publication in this journal is cited, in accordance with accepted academic practice. No use, distribution or reproduction is permitted which does not comply with these terms. 